\title{
Effect of CFO on Determination of Ventilation
}

\author{
Wei Zhou ${ }^{1}$, Ting Fang ${ }^{2}$, Qing Zhang ${ }^{3}$, Xue Ding ${ }^{4, *}$ and Zhicai Jiang ${ }^{5}$ \\ China TOBACCO zhejiang Industrial CO., LTD, No. 288, South Jianguo Road, Hangzhou, China \\ Zhengzhou Tobacco Research Institute of CNTC, No. 2, Fengyang Road, Zhengzhou, China
}

${ }^{*}$ Corresponding author

\begin{abstract}
To study the effect of total CFO airflow on ventilation determination and confirm the effect of airflow rate at filter end on measurement of actual degree of ventilation, this Paper first established 3D simulation model of standards flow field for degree of ventilation, by setting the initial condition to simulate, under different total CFO airflows, the simulation calculation value of the same ventilation standards. Meanwhile, it built experimental unit platform for ventilation determination, which is characteristic of multi-point determination and easy to control airflow rate, and total airflow of filter can be controlled by replacing CFO with different flow rates, thus the actual measurement value of the same ventilation standards can be measured and compared with simulation result of flow. Results show: on the basis of value simulation and experimental verification, CFO with different total airflows (i.e. total airflow at filter end) will have effect on measurement value of ventilation standards. With CFO flow becoming less, the measurement value of the same ventilation standards will become less gradually. When the air volume flow at outlet end of test piece is kept at $(17.5 \pm 0.3) \mathrm{ml} / \mathrm{s}$, experimental and simulation calculation all verify the maximum deviation of degree of ventilation for standards is $0.19 \%$.
\end{abstract}

Keywords- ventilation; CFO

\section{INTRODUCTION}

Ventilation is a key technical indicator for making comprehensive assessment on cigarettes and filter processing performance and quality, which is closely bound up with cigarette draw resistance. Additionally, the indicators related to total ventilation, like paper ventilation and filter ventilation, are also closely watched during production. At present, ventilation dilution is the internationally popular tar reduction means. The technology is to control inhalation quantity of cigarettes tar by human being by adjusting filter ventilation, which is widely used for it is easy and convenient as well as obvious in tar reduction. [1-5] In "GB22838.15-2009 Part 15: Cigarettes Determination of Ventilation - Definitions and Measurement Principles"[6] , it specifies measurement principles for degree of ventilation: Air is drawn by vacuum, at a constant flow, in the standard smoking direction through an unlit cigarette. The individual components of ventilation resulting from the total airflow leaving the mouth end of the cigarette aremeasured separately. The degree of ventilation is calculated. In compliance with the requirements as specified in Reference 6, the deviation from the total airflow shall not exceed $\pm 0.1 \mathrm{ml} / \mathrm{s}$; generally Critical Flow Orifice (CFO) is used to guarantee constant total airflow. Therefore CFO is the standard part for keeping constant airflow and also the key element to control airflow. Reference 6 and "JJG (Cigarettes)16-2002 Cigarette -
Verification Regulations for Critical Flow Orifice"[7] all specify total airflow at the outlet of ventilation standards shall be kept within the range of $(17.5 \pm 0.3) \mathrm{ml} / \mathrm{s}$. Diameter of CFO at $17.5 \mathrm{ml} / \mathrm{s}$ is around $3.55 \mathrm{~mm}$. For the apparatus is used to intake air for a long time uninterruptedly, the dust in the air will cause the diameter of flow orifice become smaller day by day and finally result in deviation to constant airflow produced by CFO. This Paper will build 3D simulation model of standards flow field for detecting degree of ventilation, to calculate simulation calculation value of standards for degree of ventilation at different total airflow by setting initial conditions, and analyze the effect of airflow at filter end on measurement of actual degree of ventilation; and meanwhile experimental unit platform for ventilation determination, which is characteristic of multi-point determination and easy to control airflow rate, is built up to control total ventilation airflow by replacing CFO with different flow rate, thus to measure the actual measurement value of the same standards of degree of ventilation. The measurement results shall be compared with flow simulation results to provide basis for study on general technical conditions of cigarette ventilation determination equipment.

\section{VENTILATION STANDARDS FLOW SIMULATION}

\section{A. Theoretical Investigation}

The Paper will establish 3D simulation model for ventilation standards flow field. Ventilation standards is a round glass rod with 10 capillary tubes in the middle, in which $20 \%$ of standards are a capillary tube with side opening and connected with the atmosphere; $40 \%$ of standards are two capillary tubes with side opening; and $80 \%$ of standards are three capillary tubes with side opening. Taking 20\% of standards as an example, ventilation standards equivalent simulation diagram is drawn, as shown in Figure 1.

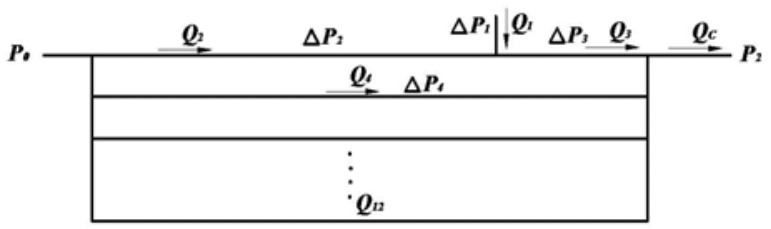

\section{FIGURE I. VENTILATION STANDARDS SIMULATION DIAGRAM}

Generally, there exists pressure loss in two forms in flow of capillary tubes, including friction resistance loss and local resistance loss, respectively as shown in Equation (1) and (2): 


$$
\Delta p_{\lambda}=\frac{128 \mu l Q}{\pi d^{4}}
$$

$$
\Delta p_{\zeta}=\zeta \frac{\rho v^{2}}{2}
$$

$$
\begin{aligned}
& \text { and } \Delta P=\Delta p_{\lambda}+\Delta p_{\zeta}=\frac{128 \mu l Q}{\pi d^{4}}+\zeta \frac{\rho v^{2}}{2} \\
& =\frac{128 \mu l}{\pi d^{4} Q} Q^{2}+\zeta \frac{\rho\left(\frac{4 Q}{\pi d^{2}}\right)^{2}}{2}=\frac{128 l}{\pi d^{4} \frac{\pi d^{2}}{4} \frac{v}{\mu}} Q^{2}+\zeta \frac{8 \rho}{\pi^{2} d^{4}} Q^{2} \\
& =\frac{512 \rho l}{\pi^{2} d^{5} \frac{\rho v d}{\mu}}+\zeta \frac{8 \rho}{\pi^{2} d^{4}} Q^{2}=\frac{8 \rho}{\pi^{2} d^{4}}\left(\frac{64}{\operatorname{Re}} \frac{l}{d}+\zeta\right) Q^{2}
\end{aligned}
$$

In which Reynolds number $\operatorname{Re}=\frac{\rho v d}{\mu}$

$$
\text { Let } \Delta P=\frac{8 \rho}{\pi^{2} d^{4}}\left(\frac{64}{\operatorname{Re}} \frac{l}{d}+\zeta\right) Q^{2}=C Q^{2}
$$

And, according to ventilation standards simulation diagram, it can be known, total airflow is the sum of airflow of different branch tubes, then

$$
\Delta P_{1}=\Delta P_{2}, \Delta P_{1}+\Delta P_{3}=\Delta P_{4},
$$

So the following relationship can be obtained:

$$
\left\{\begin{array}{l}
Q_{3}+9 Q_{4}=Q_{C} \\
Q_{1}+Q_{2}=Q_{3} \\
C_{1} Q_{1}^{2}=C_{2} Q_{2}^{2} \\
C_{1} Q_{1}^{2}+C_{3} Q_{3}^{2}=C_{4} Q_{4}^{2}
\end{array}\right.
$$

In which, $\mathrm{Q}_{1}, \mathrm{Q}_{2}, \mathrm{Q}_{3}$ and $\mathrm{Q}_{4}$ are the airflow of each branch tube, Qcis total airflow,and $C_{1}, C_{2}, C_{3}$ and $C_{4}$ are the number of each branch tube.

Degree of ventilation is

$$
V=\frac{Q_{1}}{Q_{C}}
$$

\section{B. 3D Modeling for Standards}

Taking the ventilation standards of Zhengzhou Institute that calibration value is $22.64 \%$ as the model, SolidWorks software is used to build 3D model of ventilation standards numbered V0999 as well as the model for its flow area, as shown in Figure 2 and 3. OGP is used to measure ventilation standards,

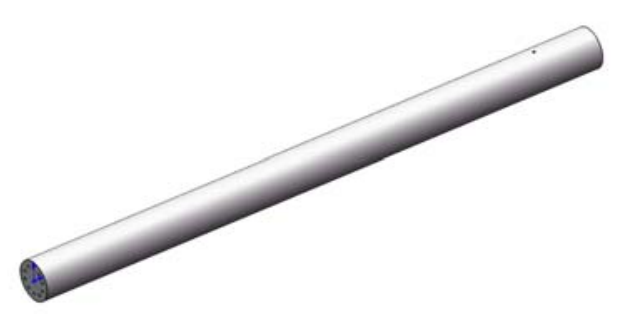

FIGURE II. 3D MODEL FOR VENTILATION STANDARDS

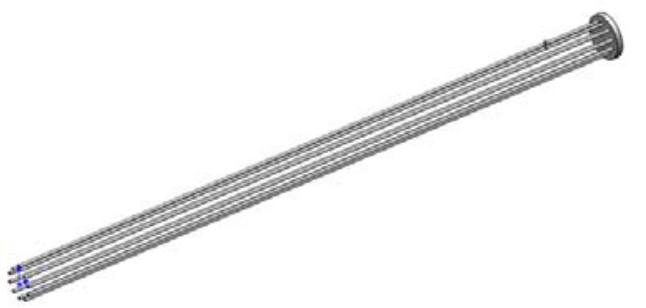

FIGURE III. CIRCULATING AREA MODEL FOR VENTILATION STANDARDS

in which diameters of capillary tubes for ten parallel main tubes are $0.54 \mathrm{~mm}$ with a total length of $119.06 \mathrm{~mm}$, and the diameter of capillary tubes with side opening is $0.474 \mathrm{~mm}$ with a length of $1.24 \mathrm{~mm}$, and the distance from the position of opening to the outlet end is $11.68 \mathrm{~mm}$. For the convenience of Fluent calculation, ten parallel main tubes section are formed a circulating area. At the outlet end of the circulating area, a column, which is $7.9 \mathrm{~mm}$ in diameter and $1 \mathrm{~mm}$ in height, is connected.

At the standard state, flow rate at the outlet is set at $17.5 \mathrm{ml} / \mathrm{s}$, due to the bore diameter of standards already known, RE value of parallel tubes can be calculated to be 282.477, and the motion of flow in capillary tubes is the motion laminar flow. Simulation calculation is made by value and obtained, at the standard flow rate of $17.5 \mathrm{ml} / \mathrm{s}$, simulated degree of ventilation is $22.963 \%$ for the ventilation standards numbered V0999, and the calibration result for the same ventilation standards made by Zhengzhou Tobacco Research Institute is $22.64 \%$, the error between the two is $0.323 \%$, less than $0.5 \%$. In accordance with the provisions under "JJG (Tobacco) 01-2012 Verification Regulation of Physical Characteristics Test Station for Cigarettes and Filter Rods"[8] , the maximum allowable error for ventilation standards is $\pm 1.5 \%$, and so the error of simulated calculation is within the specified range, stating the flow field established by this model is basically same as the flow field distribution actually measured by ventilation standards.

\section{Analog Simulation of Impact of CFO Flow on Degree of Ventilation}

Considering ventilation determination equipment is used frequently, CFO utilization in suction of air is high, and bore diameter of CFO is only $3.55 \mathrm{~mm}$, even determination equipment is always equipped with filtering device at the front end of CFO to filter micro articles in the air, but after long-term 
use, the bore diameter of CFO will become smaller inevitably and finally result in the outlet flow of CFO different from $17.5 \mathrm{ml} / \mathrm{s}$ at calibration, that is to say, CFO outlet flow is generally less than the calibrated flow after a period of actual use.

TABLE I. SIMULATION VALUES OF DEGREE OF VENTILATION FOR STANDARDS AT DIFFERENT CFO FLOW RATE

\begin{tabular}{|c|c|}
\hline CFO flow rate $(\mathrm{ml} / \mathrm{s})$ & Degree of ventilation \\
\hline 17 & $23.227 \%$ \\
\hline 17.1 & $23.174 \%$ \\
\hline 17.2 & $23.120 \%$ \\
\hline 17.3 & $23.067 \%$ \\
\hline 17.4 & $23.015 \%$ \\
\hline 17.5 & $22.963 \%$ \\
\hline 17.6 & $22.911 \%$ \\
\hline 17.7 & $22.860 \%$ \\
\hline 17.8 & $22.809 \%$ \\
\hline 17.9 & $22.759 \%$ \\
\hline 18 & $22.708 \%$ \\
\hline
\end{tabular}

Since the abovementioned flow field of this model is basically same as the distribution of flow field in ventilation standards determination, it is able to stimulate the actual degree of ventilation of ventilation standards by setting different CFO outlet flow thus to analyze if CFO total airflow will have effect on actual degree of ventilation. Table 1 shows the simulation values of degree of ventilation for standards at different CFO flow rate.

From Table 1 it can be seen, with the increase of CFO outlet flow rate, the degree of ventilation actually measured gradually becomes smaller

\section{EXPERIMENTAL VERIFICATION ON DEGREE OF VENTILATION OF STANDARDS}

\section{A. Materials, Principles and Methods}

To verify the actual degree of ventilation of ventilation standards at different CFO flow rates used in stimulation, this test also use the ventilation standards numbered V0999, and CFO flow rate is totally determined by the size of CFO bore diameter, which belongs to an uncontrollable measuring element, therefore $5 \mathrm{CFOs}$ from $17.1 \mathrm{ml} / \mathrm{s}$ to $17.8 \mathrm{ml} / \mathrm{s}$ are selected according to test demands. In compliance with " GB-T 16447-2004 Tobacco and tobacco products--Atmosphere for conditioning and testing"[9], at the test environment that ambient temperature is $(22 \pm 2)^{\circ} \mathrm{C}$ and humidity is (60 \pm 5$) \%$, first use standard flow meter ' $\mathrm{CAL}=\mathrm{TRAK}$ SL-500' to detect the flow rate of CFO, the flow rates of 5 CFOs respectively are $17.17,17.33,17.5,17.67$ and $17.83 \mathrm{ml} / \mathrm{s}$.

According to " GB22838.15-2009 Part 15: Cigarettes -
Determination of Ventilation - Definitions and Measurement Principles", definitions of degree of ventilation is the ratio of ventilation airflow and total airflow, components of total ventilation cover the air drawn in from cigarette paper and the air drawn in from tipping-paper, and the measurement principle for degree of ventilation is to measure the ventilation airflow in equipment is directly proportional to the pressure drop of laminar flow element, and so in calibration of degree of ventilation, first $100 \%$ standards is used for calibration, to measure the pressure drop of laminar flow element at $100 \%$ ventilation airflow, as well as the pressure drop of laminar flow element of test piece during actual measurement, then to obtain the flow ratio based on the ratio of the two pressure drops. The verification method, mainly by mounting CFO with different flow rates, conducts measurement to the pressure drops of laminar flow element when suction is made by standards that degree of ventilation is $100 \%$ and ventilation standards numbered V0999, and then the ratio of ventilation airflow and total airflow is calculated by the ratio of pressure drops.

\section{B. Measurement platform}

For the experimental project, a degree of ventilation experimental platform is designed. The principal diagram for the degree of ventilation experimental platform is as shown in Figure 4. The advantage of experimental platform is convenient for replacement of CFO, simple in self tubing, small in pressure drop of tubing and strong in operability and maintainability.

In degree of ventilation measurement, connect air source not less than $3 \mathrm{~kg}$ into the platform to produce negative pressure through vacuum generator (8), open solenoid valve V1 and V2, expand latex pipe by negative pressure, and put test standards into it, close solenoid valve 2 and have standards sealed, CFO (1) produces stable airflow and keep drawing-in, close solenoid valve V3, open V4, V7, wait for data of sample becoming stable, observe pressure drop of laminar flow element of standards during drawing-in through micro difference pressure transducer (5) and collect data, open solenoid valve V2 after completion, take out standards for test, and test is over.

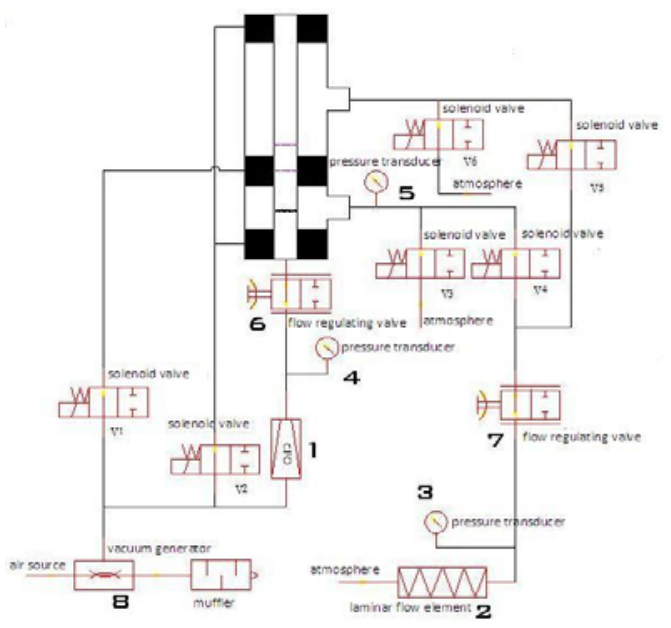

FIGURE IV. DEGREE OF VENTILATION EXPERIMENTAL PLATFORM PRINCIPAL DIAGRAM 


\section{RESUlTS AND DisCUSSION}

\section{A. Data Processing}

According to degree of ventilation measurement principles, degree of ventilation calculation method is as shown in Equation (6). Table 2 shows pressure drop of laminar flow element for 100\% standards and V0999 standards measured by $\mathrm{CFO}$ at different flow rates.

$$
V=\frac{Q}{Q_{100 \%}} \times 100 \%=\frac{P}{P_{100 \%}} \times 100 \%
$$

\section{B. Comparison Between Experiment and Simulation Data}

The comparison between experimental data and simulation data is as shown in Figure 5.

Based on the above diagram, it can clearly observed that with decrease of CFO airflow (i.e. total airflow), degree of ventilation of the same standards gradually becomes small. In accordance with the provisions as specified in "GB22838.152009 Part 15: Cigarettes - Determination of Ventilation Definitions and Measurement Principles"] 6.5 and "YCT 546-2016 General Technical Conditions for Degree of ventilation Determination Equipment of Cigarette" [10]4.15(3), CFO controlling total airflow should be $(17.5 \pm 0.1) \mathrm{ml} / \mathrm{s}$, yet because the micro foreign substances in the air are easy to block the bore diameter of CFO during drawing-in, thus resulting in airflow becoming small, and meanwhile in Clause

TABLE II. PRESSURE DROP OF LAMINAR FLOW ELEMENT FOR $100 \%$ STANDARDS AND V0999 STANDARDS MEASURED BY CFO AT DIFFERENT FLOW RATES AND DEGREE OF VENTILATION CALCULATION VALUE

\begin{tabular}{|c|c|c|c|c|c|}
\hline Flow rate (ml/s) & 17.17 & 17.33 & 17.5 & 17.67 & 17.83 \\
\hline $\begin{array}{c}\text { Pressure drop of } \\
\text { laminar flow element } \\
\text { for 100\% standards /Pa }\end{array}$ & 5.69 & 5.75 & 5.78 & 5.86 & 5.92 \\
\hline $\begin{array}{c}\text { Pressure drop of } \\
\text { laminar flow element } \\
\text { for V0999 standards /Pa }\end{array}$ & 1.3 & 1.31 & 1.31 & 1.32 & 1.33 \\
\hline $\begin{array}{c}\text { Degree of ventilation } \\
\text { calculation value }\end{array}$ & $22.85 \%$ & $22.78 \%$ & $22.66 \%$ & $22.53 \%$ & $22.47 \%$ \\
\hline
\end{tabular}

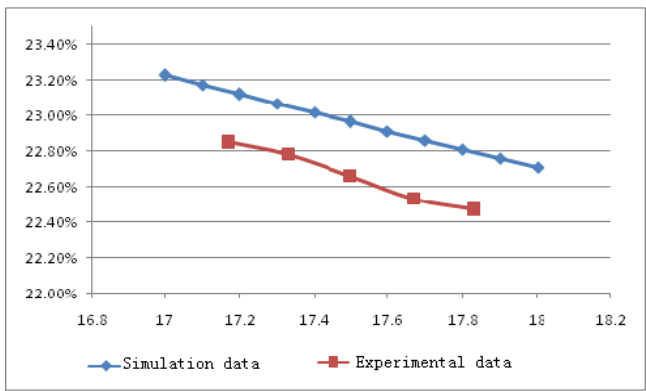

FIGURE V. COMPARISON DIAGRAM OF EXPERIMENTAL DATA AND SIMULATION DATA
4.11 under "YCT 546-2016 General Technical Conditions for Degree of ventilation Determination Equipment of Cigarette”, it specifies air volume flow-rate at outlet end of test piece shall be $(17.5 \pm 0.3) \mathrm{ml} / \mathrm{s}$, and when the air volume flowrate at outlet end of test piece is kept at $(17.5 \pm 0.3) \mathrm{ml} / \mathrm{s}$, the experiment verifies the maximum deviation of degree of ventilation for standards is $0.19 \%$, and simulation results also verify that within the flow range, the maximum deviation of degree of ventilation for standards is $0.16 \%$, and the conclusions of the two are basically the same.

\section{CONCLUSION}

Through stimulation and experimental verification, CFO with different flow rates shall have effect on measurement values of ventilation standards. With decrease of CFO airflow (i.e. total airflow), ventilation value of the same ventilation standards shall gradually become small.

According to the requirements as stated in "YCT 5462016 General Technical Conditions for Degree of ventilation Determination Equipment of Cigarette", CFO shall ensure the air volume flow-rate at outlet end of test piece to be $(17.5 \pm 0.3) \mathrm{ml} / \mathrm{s}$, and when the air volume flow-rate at outlet end of test piece is kept at $(17.5 \pm 0.3) \mathrm{ml} / \mathrm{s}$, experimental and stimulation calculation all verify that the maximum deviation of degree of ventilation of standards is $0.19 \%$, which is within the relatively reasonable range. It can be seen that, CFO during use should be detected periodically to ensure airflow is within reasonable range thus to guarantee accuracy of degree of ventilation measurement.

\section{REFERENCES}

[1] Huang Xiaofei, Yao Ermin, Wei Feng, Liu Huijie, Mo Ziliu, "Research on Degree of ventilation of Perforated Cigarettes" [J], Enterprise technical development. 2013, (5):44-45

[2] Zhou Huishun, Zong Yongli, Zhangjie, Peng Shuhai, Song Yubing, " Effects of Filter Length and Ventilation on Transfer Behavior of Some Ester Flavors in Cigarette " [J]. TOBACCO SCIENCE \& TECHNOLOGY.2010(8):41-45

[3] Cai Junlan, Han Bing, Zhang Xiaobing, Zhao Xiaodong, Liu Huimin, Xie Fuwei, "Effect of Filter Ventilation on Release of Some Aroma Components in Cigarette Mainstream Smoke" [J]. TOBACCO SCIENCE \& TECHNOLOGY.2011(9):54-60

[4] Wang Limin, Zhang Qiang, Sun Li, Ma Jianxiong, "Research on Effect of Filter Ventilation on Amount of Cigarette Smoke"[J]. An'Hui Agricultural Science. 2010(38):5108-5109

[5] Huang Xiaofei, Yao Ermin. "Research on Controlling Parameters of Cigarette Degree of ventilation" [J]. Journal of Zhengzhou University of Light Industry.2013(10):43-44

[6] GB22838.15-2009 Part 15: Cigarettes - Determination of Ventilation Definitions and Measurement Principles [s]

[7] JJG (Tobacco) 16-2002 Cigarette - Verification Regulations for Critical Flow Orifice [s]

[8] JJG(Tobacco) 01-2012 Verification Regulation of Physical Characteristics Test Station for Cigarettes and Filter Rods [s]

[9] GB-T 16447-2004 Tobacco and tobacco products--Atmosphere for Conditioning and Testing [s]

[10] YCT 546-2016 General Technical Conditions for Degree of ventilation Determination Equipment of Cigarette [s] 